\title{
REPRESENTAÇÃO CONTRA A DEMOCRACIA NO BRASIL E NA AMÉRICA LATINA Dalmo de Abreu Dallari
}




\section{O cenário trágico da América Latina}

Os povos que habitam a América Latina têm padrões culturais próprios, que exigem uma organização social e política adequada para que haja equilíbrio entre a estabilidade política, a liberdade individual e a promoção da dignidade humana.

A história da América Latina é uma acumulação de fatores negativos, internos ou vindos de fora, que até hoje bloquearam os efeitos benéficos que poderiam decorrer dos fatores positivos e geraram a imagem de impotência e incompetência dos latino-americanos para serem donos de seus destinos. Ocupada pelas potências mercantilistas do século $X V I$, a América Latina foi tratada como simples depósito de riquezas, à disposição de quem tivesse força e audácia para se apoderar delas, começando aí a prática de uma espoliação irracional e feroz, que perdura até hoje. Mudaram os métodos e os espoliadores, mas a sofisticação contemporânea, que procura criar a ilusão de independência em setores de alta tecnologia, que se refere a paises latino-americanos como "potências emergentes" e que substitui o controle pelas armas por outro controle que se exerce através da economia e dos grandes veículos de comunicação de massa, não consegue esconder a realidade: a espoliação continua, com o máximo de voracidade e sem qualquer barreira ética.

As guerras de independência que sacudiram a América Latina em fins do século XVIII e começo do século XIX tiveram pouco efeito prático, em termos de verdadeira independência e, sobretudo, de libertação dos povos. Na realidade, para as grandes massas ocorreu apenas a mudança do explorador, que em certos casos passou a ser nacional em vez de estrangeiro e que em outros apenas mudou de nacionalidade. Mas também o dominador nacional não conseguiu a independência, pois só tem conseguido manter a dominação interna graças à sua própria submissão, patente ou maldisfarçada, a dominadores sediados fora da América Latina. 
É importante assinalar que as guerras de independência tiveram efeito paradoxal, pois acabaram incentivando as divisões e os conflitos entre os latino-americanos, aniquilando as iniciativas no sentido da unidade, ou, pelo menos, da formação de grandes blocos e assim facilitando a intromissão de modernas potências capitalistas, especialmente dos Estados Unidos da América e dos grupos econômicos multinacionais. Esse dado, de importância fundamental, foi muito bemsintetizado por Pierre Bigo e Fernando Bastos de Ávila, dois eminentes sociólogos e jesuítas brasileiros contemporâneos, na obra Fé Cristã e Compromisso Social.

"O continente se esfacela em mais de 20 nações independentes. A divisão não respeita as identidades étnicas ou culturais. É definida, através de conflitos limítrofes e lutas libertadoras, segundo os interesses das oligarquias locais manipuladas pela solércia dos agentes imperiais. Independência política suficiente para exaltar os nacionalismos exacerbados mas incapaz, por isso mesmo, de criar uma resistência continental às manobras do novo colonialismo econômico. $\mathrm{O}$ capitalismo internacional incorpora, à sua órbita, a nova potência emergente, os Estados Unidos da América do Norte, e pouco depois se fecha, dividindo o mundo em dois pólos bem distintos: as economias centrais e as economias periféricas ou reflexas."

Só muito recentemente começou a tomar corpo na América Latina a consciência de que sem a efetiva unidade, não aquela formal que os governos proclamam sem convicção e sem compromisso, mas a que se funda no sentimento dos povos, será impossivel quebrar os grilhões da dependência econômica, política, social e cultural. Já se pode, com bastante realismo, afirmar que a Revolução Cubana teve papel de extrema relevância nesse processo de conscientização e que a influência de Cuba deverá crescer nos próximos anos.

Com efeito, embora houvesse nos povos da América Latina profunda admiração pela emancipação cubana, várias 
reservas permaneciam subjacentes. Havia dúvidas quanto à real possibilidade de manutenção do caminho cubano para o socialismo, em face das pressões e do bloqueio dos Estados Unidos. Por outro lado, muitos temiam que a aparente independência cubana significasse apenas a mudança do dominador, admitindo quase como fatalidade a "sovietização" de Cuba. Hoje, passados mais de 20 anos de rompimento cubano com o mundo capitalista, e já estabelecido um relacionamento muito estreito da Cuba socialista com o restante da América Latina, os temores e a incerteza estão praticamente superados. Além de ser socialista, Cuba continua, antes de tudo, "cubana" e latino-americana, exercendo uma liderança natural, conquistada na dura prática da busca permanente e bem-sucedida do equilíbrio da obtenção de recursos externos, com a preservação da independência.

Outro dado importante, na América Latina de hoje, é a convivência e superposição de dois colonialismos, um externo e outro interno. Do ponto de vista das relações com o mundo desenvolvido, a condição colonial da América Latina é evidente. Ela é fornecedora de matérias-primas e produtos básicos, sendo obrigada a receber os baixos preços impostos pelos consumidores internacionais; ela necessita de auxílios financeiros externos para enfrentar os problemas de sobrevivência de suas populações, mas por esses auxílios paga juros de alta agiotagem e é obrigada a entregar expressamente sua independência, permitindo que os credores determinem em quê e como aplicar os recursos, não sendo exagero afirmar que hoje a América Latina é governada pela dívida externa; ela é grande consumidora de tecnologia importada, que entra diretamente ou sob o disfarce de empresas formalmente - mas só formalmente - nacionais, sofrendo a sangria permanente da remessa de lucros para o Exterior e, sobretudo, do altíssimo pagamento de "royalties"; ela é consumidora forçada da produção cultural, inclusive pseudartistica do mundo desenvolvido, pagando muito dinheiro para sofrer o 
bloqueio de suas manifestações culturais e a degradação de sua cultura.

Do ponto de vista interno a situação do povo latinoamericano é a equivalente de uma condição colonial. O capitalismo interno procura avidamente associar-se ao capitalismo internacional, contentando-se com migalhas que este lhe dá e suportando as humilhações decorrentes da associação com parceiros muito mais poderosos e só preocupados com a obtenção de proveito econômico, não importa como e com o sacrificio de quem. E copiando os padrões capitalistas internacionais o poder econômico interno também não tem escrúpulos, recorrendo à coação, à corrupção, à fraude e às práticas econômicas mais injustas moralmente condenáveis, apropriando-se do produto do trabalho do povo em troca de retribuições mínimas, negando ao trabalhador e à sua família a possibilidade de viver dignamente, livres da fome, das doenças $e$ do atraso. As oligarquias latino-americanas comportam-se como colonizadores internos, tão perniciosos e injustos quanto os externos.

A conseqüência, óbvia e inevitável, desse estado de coisas é a desigualdade institucionalizada, é a legalidade como instrumento da injustiça, é a falta de liberdade para o povo, é o uso intenso e constante da repressão, é a impossibilidade de viver em paz.

\section{Ilhas de democracia formal}

Quem percorrer a história política da América Latina verificará que ela tem tido "ilhas de democracia", isoladas no tempo e no espaço, bloqueadas por ditaduras civis e militares. Embora a imagem mais freqüente, sobretudo na segunda metade do século $X X$, seja a de ditaduras militares, a verdade é que as lideranças civis, por medo ou conveniência, sempre buscam apoio militar para sustentação de seus interesses ou para lhes abrir caminho até o poder. E com isso anulam a possibilidade de uma ordem fundada no consenti- 
mento consciente e no respeito do povo, pois só mediante repressão têm a possibilidade de manter por algum tempo um poder que foi conquistado por vias antidemocráticas.

Um elemento característico nessa história é a falta de continuidade. Mesmo quando se consegue derrubar uma ditadura, encabeçada por militar ou civil, em pouco tempo outra se estabelece. Sempre se volta ao ponto de partida. Isso tem ocorrido, basicamente, porque, contrariando tendências históricas brotadas da realidade, bem como as características dessa mesma realidade social, nos momentos em que se torna possivel a implantação de sistemas democráticos os detentores do governo vão procurar soluções na idéia elitista e formal de democracia, criada pelos liberais burgueses da Europa e dos Estados Unidos nos séculos XVIII e XIX.

Isso foi assinalado por Harry Kantor, professor da Universidade da Flórida, quando observou que durante o período colonial, que perdurou até o século $X I X$, os povos da América Latina foram governados pelos colonizadores e por isso não tinham experiência de governo quando se declararam independentes. E praticamente todos se voltaram para a França, a Inglaterra ou os Estados Unidos, além de sofrer a influência dos principais escritores políticos europeus do século XVIII.

Tem razão também André Malraux quando diz que os europeus dominaram povos da América, Ásia e África e nesses lugares criaram "europeus de segunda categoria" pequenas oligarquias influenciadas pelos colonizadores, que assumiram o papel de elites intelectuais, políticas e sociais e que julgavam emparelhar-se aos dominadores imitando sua organização social e seu sistema de governo. Em tais circunstâncias, mesmo quando se adota uma forma identificada com a democracia e a partir daí se qualifica um governo como democrático não se está indo além da mera formalidade, pois as decisões foram e continuam sendo tomadas sem a participação da maioria do povo. 
Nesse quadro político não existem canais para a captação e a expressão da vontade autêntica do povo. Formalmente se adota a democracia representativa, mas o acesso aos principais cargos do governo só pode ser conseguido através dos partidos políticos, que se comportam como substitutos do povo e não como seus representantes ou veículos de sua vontade.

Os partidos, por sua vez, não passam de propostas ideológicas abstratas e imprecisas, estabelecidas no alto, por pequenos grupos de dirigentes, que falam a dominados e não a companheiros ou seguidores. Os partidos mais poderosos, que já detêm o governo ou estão na iminência de conseguilo, não são canais de expressão da vontade política do povo nem atuam como instrumentos de seus interesses fundamentais: ou representam apenas a alta burguesia ou, na melhor das hipóteses, expressam também o pensamento das camadas médias mais favorecidas, marginalizando a grande maioria do povo.

E, quando, excepcionalmente, um membro das camadas mais pobres ingressa num grande partido e consegue eleger-se para algum cargo de maior relevância é logo anulado. Essa anulação se dá pelo fato de ser vontade isolada ou, com bem maior freqüência, por cooptação ou por adesão aos segmentos dominantes. Em decorrência de fatores históricos criou-se a idéia de "classe política" para designar o grupo que detém o governo ou que gira em torno dele. E o eleito freqüentemente se considera promovido a uma classe superior, a classe política, expressão absurda e essencialmente antidemocrática, que jamais poderia ser admitida e menos ainda aplicada por quem pretende ser "o povo no governo"

Desse modo se tem anulado a vida partidária como possibilidade de realização da democracia na América Latina. Os partidos não representam o povo e não defendem ou promovem os interesses que são verdadeiramente de todo o povo. E o acesso ao governo só se dá através dos partidos ou, então, por meio de um golpe militar, o que também só serve a 
pequenos grupos, que, não por coincidência, fazem parte das camadas mais ricas ou são associados a ela.

\section{A lógica do impasse}

Nessa acumulação de fatores negativos, do passado e do presente, estão as coordenadas que conduziram o processo político da América Latina a um aparente beco sem saida. As elites sempre falaram de liberdade e de igualdade, mas a liberdade, na melhor das hipóteses, foi concebida como um direito formal, que não inclui o poder de ser livre. E a igualdade, solenemente proclamada, nunca passou de mera expressão retórica, valendo, quando muito, como garantia para os economicamente fortes ou socialmente privilegiados, mas desde $o$ ingresso dos povos latino-americanos no mundo da independência formal sempre foram adotadas Constituições consagradoras de uma desigualdade institucional mais do que evidente.

O povo, a grande maioria, permanece marginalizado, mesmo nos sistemas formalmente democráticos, porque, por intuição ou coincidência, se adotou a idéia de Hegel segundo a qual "o povo é a parte do Estado que não sabe o que quer" Por isso os lideres autonomeados, as elites politicas, se crêem com o direito e com a responsabilidade de pensar pelo povo e de decidir por ele.

Em consequência, os intentos de implantação de verdadeiras democracias na América Latina se têm dirigido por dois caminhos, que ao final se encontram no mesmo impasse:

a. um é a via eleitoral. Os partidos e os Parlamentos são frágeis e quando se implantam e se mantêm não realizam uma democracia concreta, que atinja a vida prática, limitando-se, na melhor das hipóteses, a declarações solenes de intenções ou ao exercício de formalidades ditas democráticas, sem dar ao povo, entretanto, o poder de decidir. Essas instituições não representam a garantia de liberdade e de igualdade, a não ser para pequenas parcelas das populações. 
Assim, pois, a via eleitoral não aparece como verdadeira saida para a democracia;

b. outro caminho é a via armada. Não se pode deixar de reconhecer que os povos precisam lutar com armas para se livrarem de uma opressão excessiva e até mesmo para poderem sobreviver. É um verdadeiro "estado de necessidade" coletivo e a história registra heróicas e admiráveis demonstrações de disposição para essa luta. Entretanto, a história e a consideração dos valores fundamentais da pessoa humana demonstram, por outro lado, que a violência, quase sempre, é muito mais um novo problema do que uma solução, impondo sacrifícios sobre-humanos e fornecendo pretextos para o aumento da repressão e para o apoio externo às ditaduras.

A respeito do recurso à solução armada várias outras considerações devem ser feitas. Do ponto de vista moral toda violência, armada ou desarmada, que se pratica contra um ser humano é essencialmente má. E o que se tem visto, muitas vezes, é que os movimentos armados, mesmo os mais bem-intencionados, acarretam grandes tragédias e perdas humanas irreparáveis. Além disso, quando se obtém o poder pela força sempre está presente o risco de retrocesso e por isso se necessita de continuar usando a força para manter o poder. Acrescente-se, afinal, que, como regra, num confronto armado é mais provável a superioridade de força dos sistemas dominantes, que usam o aparato do Estado e com facilidade conseguem apoio internacional.

Por todos esses motivos, a via armada não pode ser considerada como uma saída, embora em alguns casos seja inevitável recorrer a ela.

É oportuno assinalar que as atitudes ditas "modernizadoras" adotadas nos últimos anos, apoiadas em propostas de desenvolvimento econômico e racionalização do governo pelo planejamento, mudaram apenas a fachada, significaram a adoção de uma nova linguagem, cheia de cifras impressionantes, mas em nada alteraram a substância. A encenação tem sido muito rica, mas os sistemas não se democratizaram, 
o poder de decisão permanece nas mãos das elites e para amplo segmento das populações houve aumento da pobreza e da marginalização.

Criticando a falácia das doutrinas de desenvolvimento econômico, que apenas apresentam em roupagens mais sofisticadas os velhos problemas da América Latina sem oferecer soluções, o sociólogo porto-riquenho Samuel Silva Gotay faz a seguinte observação: “O desenvolvimentismo advertirá que essas economias periféricas, condenadas a serem sacrificadas para as sobrevivências das economias centrais do mercado mundial que controla seu próprio ritmo de produção, preços, sistemas de comercialização etc., pelo que só uma 'transformação integral' poderia criar o equilíbrio necessário. Com que recursos? Poupança nacional? De onde? Inversão estrangeira? A que preço? Tudo ficou em magníficos diagnósticos (que è magnífica contribuição mas não resolve o problema)"

Outra mudança formal, de superfície, que se operou nos últimos anos, sem dar solução aos problemas, foi o aparecimento dos tecnocratas, aparentemente hábeis e competentes mas, na realidade, apenas mistificadores, além de essencialmente antidemocráticos. Sobre os efeitos maléficos da tecnocracia é bem-precisa a análise feita por Pierre Bigo e Fernando Bastos de Ávila:

"Os problemas sociais, políticos e econômicos adquirem uma enorme complexidade. Para resolvê-los, em vez de mobilizar a participação popular, é grande a tentação de confiálos a herméticas tecnocracias encarregadas de enquadrá-los numa máquina de análise e decisão ainda mais complexa. Em dado momento, a tecnologia, sem a qual não é possivel formular alternativas viáveis, se transforma em tecnocracia, a qual se arroga o monopólio de optar entre as alternativas formuladas.

A tecnocracia, politicamente irresponsável, assume assim uma função eminentemente política, alienando a comunidade nacional de uma participação na solução de seus pro- 
blemas, através de seus representantes. Desse modo o povo é reduzido à condição de espectador do desempenho das tecnocracias oficiais, sociedade de espetáculo, forma de alienação coletiva incomparavelmente mais grave que aquelas previstas por Marx"

Assim, pois, de uma forma ou de outra o povo tem sido mantido à margem das decisões políticas. E não por acaso os novos métodos e a nova linguagem sempre mantiveram os desniveis sociais, a desigualdade institucionalizada, a opressão das grandes massas da população, que hoje estão mais conscientes de sua condição de oprimidas, mas que ainda não encontraram io caminho da libertação.

\section{Organização do povo: a verdadeira saida}

O caminho da América Latina para chegar à democracia passa, necessariamente, pela conscientização e organização da grande massa do povo, das imensas maiorias para as quais são dadas, quando muito, algumas ilusões democráticas, mas que nada podem e nada decidem.

A tarefa dos pensadores políticos e dos líderes é a observação atenta da realidade social, a busca de coerência entre a afirmação teórica ou programática da igualdade de todos e o oferecimento de condições concretas para que todos participem com igualdade de possibilidades. No século $\mathrm{XIX} O$ grande líder $e$ pensador cubano José Marti denunciou os pensadores políticos da América Latina como meros "importadores de idéias" Essa atitude mudou muito pouco, ampliando-se ainda mais a distância entre as análises teóricas e a realidade, uma vez que esta vem sofrendo transformações extremamente rápidas e profundas e os teóricos prosseguem utilizando modelos de análises calcados na experiência dos Estados Unidos ou da Europa.

Esse é um desafio que se põe aos teóricos da América Latina: assumir a responsabilidade de pensar a partir da realidade latino-americana. Só assim poderão contribuir para que 
se construa uma nova sociedade, autêntica e livre, na qual as formas fundamentais de organização política e social sejam o reflexo dos valores e dos interesses dos povos da América Latina.

A esse respeito continuam válidas as advertências de Marti: "Bom governante na América não é o que sabe como se governa o alemão ou o francês, mas aquele que sabe com que elementos é feito seu país e como pode orientá-los em conjunto, para chegar, por métodos e instituições nascidas no próprio país, àquele estado desejável onde cada homem se conhece a si próprio e se determina, e desfrutam todos da abundância que a Natureza deu a todos do povo que a fecundam com seu trabalho e a defendem com suas vidas. "Para que se encontrem verdadeiras soluções", diz Marti, "o governo há de nascer do país. $O$ espírito do governo há de ser 0 do país. A forma de governo há de ajustar-se à constituição própria do país. O governo não deverá ser mais do que o equilíbrio dos elementos naturais do pais."

Continua igualmente válida a observação de José Marti de que a independência da América Latina não se resume na mudança de forma, "mas na mudança de espírito"

Outra consideração importante é que não basta afirmar que os marginalizados devem participar e têm o direito de fazê-lo. É necessário todo o apoio, teórico e prático, aos grupos sociais básicos, para dar aos marginalizados a consciência de que eles, como seres humanos, devem lutar por seu direito de participação no processo político.

A par dos padrões autóctones da América Latina, que têm por base a vida comunitária, estão profundamente enraizados entre os povos latino-americanos os principios cristãos, especialmente no sentido apontado pela Teologia da Libertação, exigindo o reconhecimento da igualdade essencial de todos os seres humanos e repelindo qualquer forma de dominação. Esse conjunto de tradições e princípios coincide com os ideais de uma verdadeira democracia. Daí decorre uma exigência fundamental: assegurar aos latino-americanos 
a possibilidade de viver essa democracia, reconhecendo e garantindo a todos os mesmos direitos e a mesma possibilidade de participação.

Para que não se repita a hipócrita farsa da democracia representativa sem representação autêntica, que afinal não é democracia, é necessário ter sempre na lembrança que não basta dar o direito de participação sem assegurar o poder de participação.

Assim, portanto, é preciso apoiar os movimentos populares dos pontos de vista político, legal e material, ajudando a organização da grande massa do povo, mas deixando a cada um a efetiva possibilidade de escolher seus próprios caminhos. O movimento associativo de base é hoje uma realidade patente e vigorosa em toda a América Latina, crescendo de intensidade a cada momento, gozando de alta confiabilidade, o que não acontece com os partidos. É importante assinalar também que esses movimentos têm revelado grande capacidade de equacionar seus problemas de maior relevância e de criar meios alternativos de luta, demonstrando também muita firmeza na sustentação de suas reivindicações.

Exemplo altamente expressivo de clarividência, capacidade de sintese e objetividade no equacionamento dos problemas e na indicação das soluções é a Plataforma da Frente Unida do Povo Colombiano, redigida em. 1965 pelo padre Camilo Torres, figura gigantesca de guia espiritual, intelectual de vanguarda e guerrilheiro heróico, morto em combate nesse mesmo ano. Eis os pontos básicos da Plataforma:

"- uma reforma agrária sem indenização;

- reforma urbana que daria as residências em propriedade aos que nelas vivem;

- planejamento obrigatório do gasto público e privado;

- impostos progressivos sobre a renda; não haverá instituições isentas;

- segurança social e saúde pública garantidas; o pessoal médico funcionará na qualidade de empregados públicos; 
- sanções para os pais de crianças abandonadas;

- orçamento adequado para as Forças Armadas e defesa da soberania nacional a cargo de todo o povo;

- igualdade política para a mulher."

Não é preciso acrescentar mais para se ter a certeza de que já são conhecidos os caminhos que conduzirão os povos da América Latina à libertação, eliminando a submissão ao capitalismo internacional e os profundos desniveis econômicos, políticos e sociais internos, que hoje são causa de grande marginalização e graves conflitos, impedindo a consecução da paz. E já se sabe também que a solução dos problemas não virá por meio dos partidos políticos e dos instrumentos formais da democracia representativa, tão exaltados pelas elites ditas liberais e pelos intelectuais tradicionalistas.

Em conclusão, para se chegar à democracia autêntica na América Latina a tarefa mais urgente é desenvolver um trabalho intenso e continuado para promover a conscientização e a organização da grande massa de marginalizados da riqueza e das decisões. Com sua integração no proçesso político eles terão consciência, interesse e força para conquistar uma ordem social justa e democrática e esta não correrá o risco de reversão. Haverá paz na América Latina.

\section{BIBLIOGRAFIA REFERIDA}

Bigo, Pierre e Ávila, Fernando Bastos de, fé Cristã e Compromisso Social, São Paulo, Edições Paulinas, 1982.

Kantor, Harry, Latin American Federalism, in Federalism: infinite variety in theory and practice, editado por Valeri Earle, Itasca (lllinois), F.E. Peacock Publishers, Inc.

Malraux, André, Antimemórias, São Paulo, Difusão Européia do Livro, 1968.

Marti, José, Nuestra América, México, UNAM, Cuadernos de Cultura Latinoamericana,jvol. 7, 1978.

Silva Gotay, Samuel, Teologia de la Liberacion Latinoamericana: Camilo Torres, México, UNAM, Cuadernos de Cultura Latinoamericana, vol. 57, 1979.

FICHA CATALOGRÁFICA

Dallari, Dalmo de Abreu - "Representação contra Democracia no Brasil e na América Latina" - in Revista da Universidade de Såo Paulo - n. ${ }^{\circ}$ 2, agosto de 1986 - pág. 59 a 72 . 